\title{
A CONTEXTUALIZAÇÃO E A INTERCULTURALIDADE EM PROJETOS DE EDUCOMUNICAÇÃO
}

\author{
Edilane Carvalho Teles ${ }^{61}$
}

\begin{abstract}
Resumo
Investigar a contextualização e a interculturalidade, como conceitos que referenciam e fundamentam os projetos de educomunicação no fazer dos currículos de pedagogia é o que pretende este artigo, o qual reconhece através do intercâmbio entre culturas e realidades, uma dimensão estruturante à formação, a partir da multiplicidade dialógica na práxis de discentes e docentes, como percursos extensionistas. Assim, faz uma análise interpretativa de experiências pontuais, que incluem a mobilidade e o intercâmbio entre universidades e diferentes contextos, como proposição e perspectiva qualitativa, cujo escopo é definir e acompanhar ações entre a universidade de origem como lugar de identidade e os espaços de destino, na perspectiva de superação das fronteiras nas formações.
\end{abstract}

Palavras-chave: Contextualização. Interculturalidade. Educomunicação. Pedagogia. Formação.

\section{LA CONTESTUALIZZAZIONE E L'INTERCULTURALITÀ NEI PROGETTI DI EDUCOMUNICAZIONE}

\section{Sintesi}

Indagare la contestualizzazione e l'interculturalità come concetti che sono riferimento e sostegno di progetti di educomunicazione, nella pratica dei curricula pedagogici, è ciò che intende fare questo articolo, che riconosce, attraverso lo scambio tra culture e realtà, una dimensione strutturante della formazione a partire dalla molteplicità dialogica nella prassi di studenti e docenti, come percorsi di responsabilità sociale universitaria. Pertanto, effettua un'analisi interpretativa di esperienze specifiche, che includono la mobilità e lo scambio interculturale tra università e contesti diversi, come proposizione e prospettiva qualitativa, il cui scopo è definire e accompagnare azioni tra l'università di origine come luogo di identità e gli spazi di destinazione, nella prospettiva di superamento delle frontiere nelle formazioni.

\footnotetext{
${ }^{61}$ Doutoranda do Programa de Pós-graduação em Comunicação da Universidade de São Paulo (PPGCOM - USP); Docente da Universidade do Estado da Bahia (UNEB), Departamento de Ciências Humanas, Campus III. E-mail: ecteles@ uneb.br
} 
Parole chiave: Contestualizzazione. Interculturalità. Educomunicazione. Pedagogia. Formazione.

\title{
CONTEXTUALIZATION AND INTERCULTURALITY IN EDUCOMMUNICATION PROJECTS
}

\begin{abstract}
Investigating contextualization and interculturality as concepts that are the reference and support of educommunication projects, in the practice of pedagogical curriculum, is what this article intends to do, which recognizes, through the exchange between cultures and realities, a structuring dimension of starting from the dialogical multiplicity in the practice of students and professors, as university social responsibility paths. Therefore, it carries out an interpretative analysis of specific experiences, which include mobility and intercultural exchange between universities and different contexts, such as proposition and qualitative perspective, whose purpose is to define and accompany actions between the university of origin as a place of identity and the spaces of destination, with a view to overcoming the frontiers in the education.
\end{abstract}

Keywords: Contextualization. Interculturality. Educommunication. Pedagogy. Education.

\section{Introdução}

Para interpretar $[\ldots]$ a pedagogia deve saber dialogar. Um diálogo com outros saberes, com outras tradições culturais. Ciência e filosofia são talvez as primeiras vias do diálogo, mas não por isso as únicas. $\mathrm{O}$ diálogo crítico da pedagogia com a cultura contemporânea não pode permanecer prisioneira da dimensão do educativo e do pedagógico ${ }^{62}$. (GENNARI, 2003, p.105-106, tradução própria)

Em tempos acelerados para alguns (ROSA, 2019) ou como resultado sintomático de uma aceleração concluída, de dispersão temporal (HAN, 2018), temos vivido no contexto hodierno, o que para Martín-Barbero (2014) se configuraria em destempos entre as realidades educacional e o mundo, como um dos construtos das (in)compreensões de uma sociedade midiatizada e imbricada com as tecnologias e mídias digitais, divergindo

\footnotetext{
${ }^{62}$ Per interpretare $[\ldots]$ la pedagogia deve saper dialogare. Un dialogo con altri saperi, con altre tradizioni culturali. Scienza e filosofia sono forse le prime vie del dialogo, ma non per questo le uniche. Il dialogo critico della pedagogia con la cultura contemporanea non può rimanere imprigionato nella dimensione dell'educativo e del pedagogico.
} 
das demandas que secularmente existem no campo de formação, as quais tendem a complexizar, principalmente pelas muitas pautas dos diversos grupos que compõem a sociedade e consequentemente a formação. Por isso, a necessidade em compreender o(s) próprio(s) 'lugar(es) no mundo', de singularidade e irrepetibilidade de cada um, como direito, cujas oportunidades de acessos aos conhecimentos possibilitem ampliar as vozes dos sujeitos na reivindicação e garantias, em uma perspectiva mais democrática, (edu)comunicativa, crítica, de emancipação e liberdade de pensamentos, a partir do intercâmbio entre culturas e realidades diversas na graduação.

O presente ensaio se refere aos percursos na graduação de Pedagogia, a qual possui três dimensões necessárias às propostas de currículo: o ensino, a pesquisa e a extensão. Dentre estas, o destaque para a última citada, como um dos desafios à formação universitária na instauração e viabilização dialógica de maior aproximação com a(s) comunidade(s) e grupo(s) nos quais está situada, configurando-se assim, em oportunidades extensionistas que ampliariam e sustentariam as ações que incidirão em uma educação pautada nas multiplicidades que constituem as identidades no(s) campo(s).

Nessa perspectiva, o escopo é promover desde a matriz curricular às ações criadas e/ou implementadas, a compreensão de implicação crítica com a valorização das diferenças nas muitas formas que constituem o que somos, sujeitos que constróem as próprias identidades nas interações com os processos da vida, respeitando as dimensões e os reconhecimentos como: gênero, classe, raça, propostos em etapas de desenvolvimento diversos, os quais envolvem subjetividades e intersubjetividades, entres outras demandas, que exigem a presença(s) de percursos multi e interdisciplinares, como um dos princípios de base.

Vale salientar que tais proposições não são demandas fáceis de serem alcançadas, uma vez que nos contextos, a realização de projetos envolvendo a mobilidade e o intercâmbio entre universidades estão implicados com um movimento de sociedade direcionado a um viés neoliberal, econômico e globalizado, cuja mercantilização das coisas tendem a chegar a tudo, inclusive à educação, com ideologias homogeneizantes (GENTILI, 1995). Afinal, quais discentes e docentes participam da mobilidade e intercâmbio entre universidades? Estamos a falar de um 'pequeno grupo', que, a priori, pode ser considerado 'privilegiado', mas ao mesmo tempo, configura uma oportunidade de ampliação dos cenários das formações através das experiências quando compartilhadas, cuja presença de vozes dissonantes dos sujeitos de diferentes culturas, provocam a construção de um diálogo situado na 'diferença', um dos princípios 
necessários à interação com as diversidades que compõem os outros e o mundo, para uma convivência mais democrática e de tolerância.

Nesse sentido, como promover uma formação inicial na pedagogia, compreendendo as muitas dimensões que precisa ter? Uma das possibilidades de resposta está nos princípios e proposições da interface entre os campos educação, comunicação e outras áreas de conhecimentos, entre estes, a educomunicação, os quais contribuem através dos desafios postos nos processos didático-pedagógicos, ações que inferem em um viés de aproximações conceitual, epistemológica e metodológica, de imbricamento com as realidades. Ulteriormente impulsionada quando as ações são realizadas nas experiências do intercâmbio.

As análises a seguir compõem uma reflexão sobre a mobilidade e intercâmbio discente entre o Departamento de Ciências Humanas, Campus III, UNEB (Bahia, Brasil) e a Universidade de Padova (Região de Veneto, Itália), de discentes do curso de pedagogia das duas instituições, vislumbrando a possibilidade de entendimentos das aprendizagens na participação em disciplinas e projetos das instituições.

Assim, como não poderia ser diversamente, a formação insere-se em um contexto de multiplicidades das identidades culturais, de pertencimento (étnicas, raciais, linguísticas, religiosas, nacionais) que expressam e emergem nas/das realidades, lugares de construção das mediações e intersecções possíveis, através das ações (edu)comunicativas (Brasil e Itália), entre elas, o intercâmbio entre os grupos, que ocorre com a mobilidade discente e docente nos espaços-tempos, entre a universidade como origem propositiva e a oportunidade de inserção nas instituições (formais e não-formais) ou ainda, espaços informais, como um dos modos do fazer nos percursos. Entretanto, apesar do (re)conhecimento, este é também uma reflexão sobre a limitada capilaridade das experiências nesta perspectiva nas graduações, em especial nos cursos de licenciaturas e de pedagogia, as quais não são de acesso a todos.

A pedagogia é um grande desafio, principalmente por ser em perspectiva e objetivo de campo, a formação do profissional que atuará nos diversos segmentos da sociedade que incluem processos educativos/comunicativos/formativos, cuja delimitação está muito além das próprias fronteiras, constituindo/instituindo as dimensões que pode(m) ter seu(s) objeto(s) de investigação e ação, através do diálogo aberto às diferenças com outros campos de conhecimentos, nos movimentos e transformações do próprio entorno e devir na atuação profissional. 
Ou seja, a formação do pedagogo diante dos contextos e demandas interculturais não deveria limitar-se a conteúdos específicos de áreas de conhecimentos como foi (e ainda é) estruturada. Pois, assim posta, referencia uma perspectiva de educação bancária, ao contrário do que deveria promover, como afirmava Freire (1987), uma educação como lugar de liberdade e emancipação das pessoas, de intercâmbio e da dúvida, que busca a compreensão da(s) realidade(s) e nesta(s) inferir, a partir da própria participação com os outros no mundo.

Nesse sentido, faz-se necessário a realização de um exercício de memória, para o resgate das experiências construídas durante a formação inicial em pedagogia e as referências posteriores à docência, as quais deixam um diversificado lastro hermenêutico da práxis no campo. Esse entendimento será apresentado em três possibilidades temáticas consideradas na construção: (a) a inter-relação da pedagogia com a perspectiva de um diálogo contextualizado e intercultural, (b) a relevância das experiências construídas no(s) entremeio(s) das culturas e realidades sociais, locais e globais que deveriam ser/estar na centralidade da formação, a qual propõe como campo profissional, (c) a educação a partir dos contextos, com os escopos de aprendizagens que superem as próprias fronteiras de conhecimentos sobre a(s) diversidade(s) na interface dos campos.

\section{A pedagogia na perspectiva da contextualização e a interculturalidade}

O exercício de memória está relacionado à indagação sobre os lugares, espaçostempos por onde perpassam as formações. Assim, a sistematização do presente estudo tem sua gênese na participação do I Colóquio Brasil-Itália ${ }^{63}$, o qual possibilitou uma interpretação dos processos de internacionalização, bem como uma análise metacognitiva sobre os percursos comunicativos/educativos/formativos, a partir da proposta de intercâmbio entre a UNEB (Universidade do Estado da Bahia, Brasil) e a UNIPD (Università di Padova, Itália), como uma oportunidade formativa além das fronteiras do estado e país.

Tal perspectiva relaciona-se ainda com a participação de discentes do intercâmbio em projetos de educomunicação (EDUCOM) no curso de pedagogia, ação pontual que

63 I COLÓQUIO BRASIL-ITÁLIA. A educação contextualizada e o diálogo intercultural na implementação de novas estratégias de internacionalização da extensão no PPGESA DCH III/UNEB. Programa de Pós-graduação Mestrado em Educação, Cultura e territórios semiáridos. Departamento de Ciências Humanas, Campus III, Universidade do Estado da Bahia. 31/07/2019 e 21/08/2019 a 23/08/2019. In: http://www.coloquiobrasilitalia.com 
propõe pensar sobre o encontro de identidades culturais, currículos distintos na realização de práticas que atendam a formação e a dimensão dialógica entre instituições, nas ações, cujo processo implica na centralidade e ampliação do conhecimento de si, a partir do diálogo com o(s) outro(s), em uma perspectiva local e global. Por isso, a emergência das memórias através das histórias de vida (JOSSO, 2004; SOUZA, 2006), com as quais a hermenêutica das experiências, desafia e reconhece sua relevância no entendimento dos conceitos e metodologias envolvendo a interculturalidade, como proposta de convivência democrática.

A escolha por estas duas categorias foram individualizadas nos processos de investigação e realização dos projetos, pois são partes essenciais à epistemologia dos contextos, os quais deveriam compor as bases teórico-metodológicas desde o processo de entrada, permanência e estudos da graduação, com vistas a consolidar uma atuação profissional no campo da diversidade e as aprendizagens necessárias para uma sociedade democrática e cidadã, pautada nos valores éticos e fraternos na perspectiva (edu)comunicativa e de respeito às diferenças.

Assim, se propõe como um convite à reflexão da universidade, como um lugar de abertura à multiplicidade de saberes, que provoca constantemente a dúvida diante das (in)certezas do mundo e coerência com as escolhas que faz, como, por exemplo, as extensões com as comunidades, ou assim deveria ser. Portanto, para abordar os conceitos, o percurso é o de valorização e produção de conhecimentos, a partir da(s) realidade(s) com os projetos de EDUCOM.

Neste processo, o currículo é resultado do diálogo e imbricamento, que se constitui a partir das lutas e disputas nos territórios, projetando-se como desafio na construção das mediações (ARROYO, 2013). Entretanto, em detrimento de um distanciamento identificado nos contextos, promove, muitas vezes, uma formação estéril que pouco interage com as pessoas nas comunidades, não atendendo as reais exigências sociais, culturais e (edu)comunicativas, por isso, a contextualização como sustentação das propostas, uma vez que é a partir do conhecimento de si e do entorno, com as muitas demandas e divergências discursivas, que são construídas, com as 'distorções' presentes (e necessárias) para romper com as barreiras que são erigidas. Pois,

Quanto mais a vida social se torna mediada pelo mercado global de estilos, lugares e imagens, pelas viagens internacionais, pelas imagens da mídia e pelos sistemas de comunicação globalmente interligados, mais as identidades se tornam desvinculadas - desalojadas - de tempos, lugares, histórias e tradições específicos e parecem "flutuar livremente". Somos confrontados por uma gama de diferentes 
identidades (cada qual nos fazendo apelos, ou melhor, fazendo apelos a diferentes partes de nós), dentre as quais parece possível fazer uma escolha. (HALL, 2006, p. 75)

Nesta perspectiva, a pedagogia precisa ampliar as próprias fronteiras e entendimentos, assim como a inclusão dos movimentos que chegam com os percursos comunicativos e didático-pedagógicos, exigindo, portanto, pensar além do educativo, pois os conhecimentos não são estanques, assim como, as formas como os sujeitos lidam com as referências através das apropriações no campo educacional. Os quais, constantemente têm sido provocado a 'sair das bolhas' (FERRARI, 2018) que criaram para si mesmos, sendo postos em xeque principalmente pelas demandas de grupos sociais e políticos que acreditam saber mais que o próprio campo. Assim, encontra-se entre demandas distintas, a sociedade que exige mudanças e resultados e a educação que pauta principalmente seu modus operandi no pedagógico.

O momento atual é de busca de referenciais que defendam a educação como 'prática de liberdade' (FREIRE, 1983) e reconhecimento como campo que tem condições de sustentação das construções que promove. Pois entre as transformações de dentro e fora dos espaços educacionais, as direções nem sempre convergem, ao contrário, cada vez mais, os discursos sustentados nas 'nuvens' fakes e de senso comum, é de que a educação precisaria de 'decisões mais firmes', 'totalitária e neutra'. Todos discursos perigosos pelos movimentos que provocam.

Estamos diante da falência da educação? O curso, assim como o campo não teriam mais o que propor, por isso as desconstruções de fora para dentro? A priori, é preciso insistir no diálogo e nas construções formativas como respostas às problemáticas comunicativas/educativas que chegam às instituições, em especial, no contexto das escolas públicas, por serem o lugar de direito onde acontece a educação das maiorias (TELES; SILVA, 2018). Entretanto, a formação não pode construir as muitas saídas se não realiza aprofundamentos culturais, sociais, criativos, científicos e teóricometodológicos de fortalecimento de si, do campo e das ações. A educação ainda é o lugar da 'conversação necessária' (TURKLE, 2016), na qual as diferenças não deveriam ser repelidas, mas aceitas, compreendidas e respeitadas nas suas inteirezas e complexidades.

Outro aspecto que promove as inter-relações está situado nas áreas de interesses dos grupos e instituições que promovem os currículos. Por isso, a indagação sobre qual educação e formação estamos a falar e queremos promover. Se o escopo é o respeito à convivência com as realidades diversas que temos no entorno do semiárido, por exemplo, 
a delimitação deveria fundamentar-se na contextualização como princípio de construção dos pensamentos e interpretação, relacionando à(s) carga(s) subjetiva(s) que encontra(m) na(s) intersubjetividade(s) dos espaços-tempos, os movimentos das pessoas e os discursos que elaboram e assumem como próprios. É desta forma que a universidade entra no entendimento aqui proposto, como um convite para realizar estudos sobre as categorias levantadas. Minimamente dizendo, como amplitude das perspectivas dos processos educativos ao longo da vida. Uma vez que,

\begin{abstract}
A temporalidade da formação, tal como pode ser verbalizada e socializada numa narrativa de vida, é excepcionalmente contada como um milagre de instantaneidade. É o tempo de realizar uma tomada de consciência e de fazer um trabalho de integração e de subordinação que pode levar alguns minutos, algumas semanas, alguns meses, alguns anos ou até mesmo toda uma vida: fazer com... para se dar forma; fazer com... no tempo para transformar o meu tempo em experiências formadoras de competências e de qualidades. (JOSSO, 2004, p. 206)
\end{abstract}

A educação e as pessoas que chegam até ela são diversas, nesse sentido, é uma proposição sem retorno que as práticas deveriam assentar-se nos princípios da democracia e das diferenças das vozes nos cenários educacionais como aprendizagem, de participações ativas e críticas. Para isso, docentes e discentes precisam construir experiências para além dos discursos pedagógicos elaborados para proferir as 'melhores possibilidades' do agir na educação.

\title{
As experiências entre culturas e realidades sociais
}

Uma das críticas recorrentes aos currículos e práticas de formação refere-se às limitadas imersões nas realidades, da ausência de projetos que construam diferenças conceituais e metodológicas 'propositivas e positivas', uma vez que sustenta seus discursos, quase exclusivamente no campo educativo e pedagógico como principal referência. Escolha que pode incorrer em um grande equívoco, uma vez que o profissional que se pretende formar possui demandas que ultrapassam muito as áreas delimitadas, as quais deveriam estar nas bases da educação dos povos.

Assim, questiona-se por que as ações não estão atravessadas pelas experiências no fazer acadêmico? Ao invés de serem proferimentos relacionados à 'falta' nos contextos e processos que precedem as ações profissionais, principalmente quando os discentes destacam que, ao que parece, são duas dimensões presentes, a teoria e a prática, esta última relacionada ao fazer. Nesse entendimento, de hermenêutica da pragmática 
discursiva (ARAÚJO, 2004), comumente relacionado apenas ao 'dizer e o dito', faz-se necessário também para referir-se às construções cotidianas incluídas como parte da(s) estrutura(s) do que virá a ser a práxis docente, ou seja, dos discursos que incidem na prática pedagógica.

Nesse sentido, envolvem as experiências, que mais 'dizem' sobre os processos e percursos do que demonstram, uma vez que seguem nos cursos, a questionada 'ausência' das ações que as redimensionariam, como, por exemplo, mais práticas, mais ações, mais mobilidade. Constatação óbvia, que merece estar continuamente presente, pois as preocupações com planos, aulas e conteúdos envolvidos têm em muitos contextos, uma forte tendência totalitária a ideias fragmentadas sobre o que as pessoas deveriam aprender dentro dos muros das escolas. Fala-se em emancipação e liberdade, mas para promover é preciso sê-lo. Por isso, o (re)conhecimento de si como 'ação' primeira da formação, em seguida a 'inter-relação' destas compreensões com a realidade e o entorno e, por fim, a continuidade das investigações para a diversidade. Pois, "[...] a experiência, e não a verdade, é o que dá sentido à educação.” (LAROSSA, 2018, p.5)

A proposta é de que os currículos e as práticas sejam também diversas, de experimentação com os projetos de ensino, pesquisa e extensão, transversalizando as relações interculturais nos componentes curriculares e todo o curso. Se o objetivo é uma educação de respeito e tolerância aos princípios aqui destacados, os percursos didáticopedagógicos devem propiciar o encontro. Os quais, devem ser ainda, realizados em parceria com a(s) comunidade(s) na perspectiva interdisciplinar, transdisciplinar e transversa, de amplitude e clareza sobre o campo e a atuação de um profissional que está muito além do(s) conteúdo(s). Deixando claro que sua relevância está implicada na própria afirmação como ciência e aprofundamentos dos estudos, na intelectualidade e na produção de conhecimentos que movem as ações, superando a repetição de teorias, pois para transforma e educação é preciso criá-las. Ou seja, o escopo não é de negação dos saberes e conhecimentos referendados no currículo formal como menores, mas de investigá-los com o compromisso da contextualização, aprender compreendendo os sentidos e significados para o próprio processo cognitivo e metacognitivo, das aprendizagens para o campo profissional futuro.

Para tanto, os projetos (edu)comunicativos e extensionistas precisam ser um aspecto estrutural das propostas, os quais não apenas interligam-se com a realidade como se constituem neste lugar onde situam os intercâmbios e os encontros, como, por exemplo, 
o citado no início deste artigo, com as muitas possibilidades que promoveu à universidade, como a internacionalização e o diálogo com outras culturas.

Portanto, questiona-se uma pedagogia historicamente construída em um discurso elaborado na referência da criação contínua na interface dos campos (educação e comunicação), mas que em muitas realidades pouco tem incidido, a citar, como exemplo, os projetos realizados a partir da imersão com os processos e meios comunicacionais, incluindo as mídias e tecnologias, em muitos movimentos que transitam entre ações pontuais na realização de pesquisas, práticas do estágio curricular e projetos de extensão relacionados aos componentes curriculares, sem, contudo, haver continuidade como parte dos contextos além das ações da universidade, ou seja, acontecem entre fragmentos e interrupções. Nesse sentido, cabe refletir que

O campo científico é um conjunto de propriedades que são o produto de atos de conhecimento e de reconhecimento completados por agentes envolvidos com o campo científico e dotados, portanto, de categorias de percepção específica que consentem a estes estabelecer as diferenças pertinentes, conforme o princípio de pertinência constitutivo de nomos do campo. Esta percepção diacrítica é acessível somente aos detentores de um capital cultural incorporado suficiente. (BORDIEU, 2003, p. 73, tradução própria) ${ }^{64}$

Diante disso, a Educomunicação com a necessária construção de experiências para um possível redimensionamento nos modos como vêm a práxis pedagógica, pautada no respeito às diferenças e na atenção com as interpretações sobre a transversalização dos percursos de mediações discentes e docentes, geralmente limitadas à investigação de temáticas contextualizadas para relacionar aos conceitos científicos, considerados de forma reincidente, como atividades pontuais e/ou avaliativas de registros à formação.

O conhecimento científico e acadêmico podem/deveriam ter diante das transformações, o rigor epistemológico e de cotidianidade, necessários para entender a miriade e rápida quantidade de interações que retiram dos tempos do pensar, a promoção e construção de outros entendimentos sobre as coisas, de revisitação das proposições formativas também pela 'forma' como tem-se visto e/ou reduzido em ações fragmentadas,

\footnotetext{
${ }^{64}$ Il capitale scientifico è un insieme di proprietà che sono il prodotto di atti di conoscenza e di riconoscimento compiuti da agenti impegnati nel campo scientifico e dotati perciò delle categorie di percezione specifiche che consentono loro di stabilire le differenze pertinenti, conformi al principio di pertinenza constituitivo del nomos del campo. Questa percezione diacrítica è acessibile solo ai detentori di un capitale culturale incorporato sufficiente.
} 
que nos dias de hoje estão muito distantes da gênese em technè e poiesis, como arte e criação que fundamentam as reflexões.

O intercâmbio destacado tem um longo histórico na UNEB (BAHIA, 1997) e, mesmo com limitadas participações, pois apenas dois departamentos realizaram o intercâmbio (DEDC I ${ }^{65}$ e DCHIII ${ }^{66}$ ), ambas foram promovidas pelo interesse pontual de pesquisadores. Entretanto, vale salientar que a realização abre algumas questões importantes: a internacionalização da universidade, a curricularização da extensão e aprendizagens construídas com as experiências, as aprendizagens decorrentes do encontro como outras culturas fora do próprio contexto, a possibilidade da troca de conhecimentos que configuram um dos princípios de discussão da interculturalidade e a convivência. Assim,

\begin{abstract}
A educação, na perspectiva intercultural, deixa de ser assumida como um processo de formação de conceitos, valores, atitudes baseando-se uma relação unidirecional, unidimensional e unifocal, conduzida por procedimentos lineares e hierarquizantes. A educação passa a ser entendida como o processo construído pela relação tensa e intensa entre diferentes sujeitos, criando contextos interativos que, justamente por se conectar dinamicamente com os diferentes contextos culturais em relação aos quais os diferentes sujeitos desenvolvem suas respectivas identidades, torna-se um ambiente criativo e propriamente formativo, ou seja, estruturante de movimentos de identificação subjetivos e socioculturais. (FLEURI, 2003, p. 31-32)
\end{abstract}

Pensar, portanto, as inter-relações na formação e nas ações que ocorrem além da graduação, como possibilidade e promoção do intercâmbio de estudantes entre as Universidades. Neste, além da mudança de contexto, cultura, relações sociais, demandas pessoais, exigências inter-pessoais e de conhecimentos, são diversos, o que por si, constitui uma outra aprendizagem com abordagens, distanciamentos e aproximações direcionados a deslocamentos e interpretações de aspectos não previstos no currículo formal. Desta forma, ao fazer as opções pelas disciplinas e participações nos projetos, abre-se à investigação em áreas e componentes daqueles que os currículos de origem dialogam, constituindo assim, uma oportunidade marcante pelas diferenças culturais e acadêmicas de internacionalização e mobilidade.

\footnotetext{
${ }^{65}$ Departamento de Educação, Campus I, Salvador, BA.

${ }^{66}$ Departamento de Ciências Humanas, Campus III, Juazeiro, BA.
} 


\section{Aprendizagens e diversidades de conhecimentos na interface dos campos, a EDUCOM}

Como sujeitos forjados na cultura e nos contextos sociais, as referências às experiências construídas estão sempre emergindo no campo das mediações e relações. Os projetos de EDUCOM realizados no âmbito da formação do pedagogo do DCH III no núcleo de Educação e Comunicação (BAHIA, 2011) têm provocado este viés interdisciplinar, intercultural e (edu)comunicativo das propostas de intervenção nos espaços formais, não-formais e informais. Algumas características da proposta, assim como da área de referência subsidiam as práticas contextualizadas, como medium de aprendizagem verso si mesmo e o respeito dialógico com as comunidades e espaços que acolhem as ações.

Nesta perspectiva os projetos de mobilidade partem da experiência viva de interação com os contextos e realidades narradas e expressas pelas pessoas. Assim nascem os projetos, demandados das necessidades dos grupos, com os quais busca-se interagir e construir percursos e processos interpretativos de investigação das temáticas e problemáticas que emergem como urgentes. Na metodologia alguns procedimentos são elaborados, como:

A. a ida à realidade para conhecer o que é possível aos olhos daquele que vêm de fora, por isso, o levantamento de dados com os sujeitos nos espaços, com questionários, entrevistas, rodas de conversas e outros instrumentos que ajudem na aproximação do que se constitui de fato como problemas 'reais' e não apenas temáticas de pesquisa da universidade;

B. os estudos contínuos com os grupos nas tentativas de aprofundamentos no tratamento científico dos objetos que aparecem como relevantes;

C. o processo de aproximação e pesquisa, no qual ocorre ainda a gestão dos meios comunicacionais que aparecem nos discursos e ações, uma vez que fazem parte das relações, do compartilhamento de saberes, assim como, os desafios postos pelos avanços das tecnologias e mídias, que exigem uma ulterior investigação crítica, assim, se escolhe os meios por onde as elaborações irão perpassar, que podem ser através da socialização das produções construídas que efetivam-se de muitas formas, como, por exemplo, a fotografia, o rádio comunitário, o jornal, a produção de autobiografias ou textos de muitos modos, a arte nas suas muitas manifestações, como a pintura, o teatro, a música, entre tantas outras, pois os construtos não são definidos e sistematizados 
pelos graduandos que coordenam o projeto, mas por todos o(s) protagonistas(s) e colaborador(es), as pessoas para os quais são criados.

No âmbito do intercâmbio/mobilidade discente entre as duas universidades, dois projetos foram realizados na perspectiva da EDUCOM, com participação de estudantes da UNIPD e da UNEB: O primeiro realizado para mulheres em situação de risco, denominado "Projeto de Mediação Social: Mulheres, sabor e arte" (2018), tinha como proposta refletir a interação entre práticas profissionais para mulheres que vivenciam o projeto da pastoral da mulher. Este, por ser realizado em um contexto de vulnerabilidade e sistematização próprios, a educomunicação não se efetiva como uma construção autoral das protagonistas, pois foi direcionado pelos limites apresentados institucionalmente, como um espaço de rodas de conversas, escuta e oficina de arte e culinária; o segundo, realizado no CASE (Comunidade de Atendimento Socioeducativo), com adolescentes menores infratores, também escolheu a arte como referência (2018). Se intitulou "De dentro para fora: Uma proposta educomunicativa", o qual buscou refletir a expressão artística dos jovens em semiliberdade, através do olhar fotográfico sobre o mundo e o entorno.

As propostas foram definidas a partir das expressões e demandas colhidas nas vozes e interesses dos sujeitos, os quais apresentavam com as problemáticas que envolvem suas vidas, um processo de "exaustão", como afirmavam, diante das barreiras da violência, do fracasso escolar e da pobreza, entre outras, difíceis de mapear e acompanhar, tamanha é a complexidade encontrada.

O segundo projeto, pela possibilidade de construção de todas as etapas do projeto de EDUCOM, nos limites que apareceram, deixaram uma presença mais marcante. Da real criminalização destes jovens privados de apoio e acompanhamento, sujeitos à violência e, por conta disso e outros motivos, participaram entre interesses e desinteresses, entretanto, com respostas que surpreenderam nas lentes das máquinas fotográficas, emocionando os mediadores do projeto, assim com, todos os que tiveram a oportunidade de ver a exposição das fotos, além dos depoimentos, que

[...] apresentam um discurso de dor e exaustão, de ter que viver "como um pássaro em uma gaiola bem pequena, capaz de sufocar", palavras ditas por John um dos jovens da CASE, que expressa o sentimento de tantos outros que lá convivem, e na maioria das vezes, preferem se calar. Sonham com a liberdade, com a possibilidade de correr livre em uma rua, de ver a família, de poder abraçar a mãe, de estar em seus lares e estar diante de todo o contexto onde antes viviam. (TELES; SILVA; RODRIGUES, 2018, p.3, grifo dos autores para informar que o nome é fictício) 
Foram apenas duas experiências que ao serem sistematizadas pelo grupo, mudam não apenas aqueles que viveram em primeira pessoa a oportunidade dentro dos projetos, como todos aqueles que interagem de outras formas. A inserção na realidade e contextos das pessoas é um mergulho muito complexo que necessita de maiores reflexões no campo acadêmico e, ao mesmo tempo, com a inclusão de 'estratégias sensíveis' de escuta e abertura às emoções de todos os que participam, o que acarreta de mais tensão. Pois, "É na realidade uma preocupação com o que está aquém ou além do conceito, isto é, com a experiência de uma dimensão primordial, que mais que ver com o sensível do que com a razão. (SODRÉ, 2016, p. 22)

Assim, os projetos vão sendo desenhados pelos grupos num diálogo necessário com a universidade e a graduação, nas tentativas e buscas por respostas às demandas reais que os envolvem.

\section{Considerações finais}

Este ensaio propôs refletir a formação do pedagogo na perspectiva da contextualização e da interculturalidade como sustentação das ações formativas com os projetos de EDUCOM. É urgente a superação de discursos sobre os fracassos educacionais que incidem e são decorrentes do 'colapso' social que persegue a educação baiana e brasileira, como, por exemplo, a não erradicação do analfabetismo, a não conquista de uma educação pública de qualidade para as maiorias, a desafiante proposta de formações que ampliem as 'leituras de mundo' das pessoas, assim como, estudos consolidados na pedagogia de inclusão das muitas 'vozes'. Este é o primeiro desafio, olhar a realidade e promover uma formação na qual sejam contempladas e inseridas todas as pessoas, com vistas ao fortalecimento e (re)conhecimento de que fazem parte do mundo com as diferenças que possuem.

Entretanto, o que percebe-se em muitos currículos são os modos de atuação e construtos de muitos grupos que sugerem a partir das próprias intencionalidades, o que propõem à educação, muitos dos quais não respondem às demandas urgentes de inclusão e atendimentos dos serviços básicos, agregando à complexidade presente, questionamentos limitados e de retrocesso como, por exemplo, a militarização das escolas (ARROYO, 2019), colocando em crise não apenas a pedagogia, como também uma educação mais humanitária e solidária a todos, criminalizando crianças e jovens da 
periferia e do campo. Por isso, o convite aos projetos extensionistas, de mobilidade e intercâmbio entre universidades, como uma abertura para repensar as próprias práticas pedagógicas e o campo de conhecimento. O compromisso da pedagogia é com as realidades e os sujeitos que destas fazem parte com suas singularidades, individualidades e diferenças, criando ações criativas mesmo diante das limitações e dificuldades.

Dito desta forma é preciso propor os esclarecimentos e as colaborações com as nuanças que emergem no fazer com a continuidade destes processos na formação inicial com o intercâmbio UNEB-UNIP, como:

- A aprendizagem das diferenças das identidades culturais, desafiando a pensar mais sobre a tolerância e o respeito;

- Conhecimento de outras línguas, como amplitude de formação nas duas realidades, para todos os participantes, que ao conviverem com a universidade no intercâmbio, adquirem maior apropriação e domínios comunicativos, o que potencializa os aspectos da linguagem e da comunicação em contextos internacionais e locais;

- A interação e conhecimento de outras proposições, pois os currículos diferem de uma universidade para outra, ampliando, portanto, os entendimentos dos contextos sócio-históricos, culturais, conceitual, epistemológico e teóricometodológico, muitas vezes apenas possíveis somente em experiências destes formatos;

- A consciência do papel de acadêmico e pesquisador, que identifica na oportunidade formativa experiências pontuais, que farão parte do arcabouço reflexivo;

- A criação de ações no percurso de planejamento, realização e sistematização dos projetos nas universidades, com devolutiva às comunidades e os protagonistas.

Por fim, a compreensão de que tais colaborações atuam de forma tensa e intensa com a troca de conhecimentos, culturas, contextos e pesquisas em diversas problemáticas e temáticas no campo de formação, tendo ainda a certeza, de que tais decisões promovem o desenvolvimento recíproco de atividades em nível científico, didático-formativo nos espaços e campos. 


\section{Referências bibliográficas}

ARAÚJO, Inês Lacerda. Do signo ao discurso: introdução à filosofia da linguagem. São Paulo: Parábola Editorial, 2004.

BAHIA. Universidade do Estado da Bahia / ITALIA. Università degli Studi di Padova. Accordo di collaborazione tra la Facoltà di Scienze della Formazione dell'Università di Padova (Italia) e la Facoltà di Educazione FAEEBA dell'Università dello Stato di Bahia (Brasile). Valido per gli anni (1997, 1998, 1999) (Mimeo)

Universidade do Estado da Bahia. Departamento de Ciências Humanas. Comissão de Reformulação Curricular. Projeto de reconhecimento do Curso de Pedagogia - Licenciatura. Campus III. Colegiado do Curso de Pedagogia. _ Juazeiro: O departamento, 2011.

ARROYO, Miguel G. Currículo, território em disputa. 5. ed. Petrópolis, RJ: Vozes, 2013.

.Escolas militarizadas criminalizam infâncias populares. Entrevista de

Miguel Arroyo cedida a Ana Luiza Basilio. In:
https://www.cartacapital.com.br/educacao/miguel-arroyo-escolas-militarizadascriminalizam-infancias-populares/In: 26/10/2019.

BORDIEU, Pierre. Il mestiere di scienziato. Milano: Italia: La Feltrinelli, 2003.

FERRARI, Pollyana. Como sair das bolhas. São Paulo: EDUC, 2018.

FLEURI, Reinaldo Matias. Intercultura e Educação. Revista Brasileira de Educação. $\mathrm{N}^{\circ}$ 23, Maio/Jun/Jul/Ago, 2003, p.16-35.

FREIRE, Paulo. Educação como prática da liberdade. 14a. ed. São Paulo: Paz e Terra, 1983.

Pedagogia do oprimido. 23a. Edição. São Paulo: Paz e Terra,1987.

GENNARI, Mario. Interpretare l'educazione. Pedagogia, semiotica, ermeneutica. Brescia, Italia: editrice La scuola, 2003.

GENTILI, P. Adeus à escola pública: a desordem neoconservadora, a violência do mercado e o destino da educação das maiorias. In: SILVA, L. H. da; AZEVEDO, J. C. (Org.). Paixão de aprender II. Petrópolis: Vozes, 1995. p. 358-379.

HALL, Stuart. A identidade cultural na pós-modernidade. 11. ed. -Rio de Janeiro: DP\&A, 2006.

HAN, Byung-Chul. Il Profumo del tempo. L'arte di indugiare sul cose. Milano, Italia: Vita e Pensiero, 2018.

JOSSO, Marie-Christine. Experiências de vida e formação. São Paulo: Cortez, 2004.

LAROSSA, Jorge e KOHAN, Walter (coord.) Elogio da Escola. 1. ed. Belo Horizonte: Autêntica Editora, 2018.

MARTIN-BARBERO, Jesús. A comunicação na educação. São Paulo: Contexto, 2014.

ROSA, Hartmut. Aceleração. A transformação das estruturas temporais na Modernidade.

São Paulo: Editora UNESP, 2019. 
SILVA, Elis. Rejane S. ; TELES, Edilane Carvalho; RODRIGUES, Jaqueline Aquino. Educomunicação Cabocla no semiárido baiano: reflexões sobre a práxis. In: $\mathbf{4 1}^{\circ}$ Congresso Brasileiro de Ciências da Comunicação, 2018, Joinville - SC. Intercom 2018 Univille. São Paulo: Intercom ? Sociedade Brasileira de Estudos Interdisciplinares da Comunicação, 2018. p. 1-13.

SODRÉ, Muniz. As estratégias sensíveis: afeto, mídia e politica. 2. ed. Rio de Janeiro: Mauad X, 2016.

SOUZA, Elizeu Clementino de. O conhecimento de si. Estágio e narrativas de professores. Rio de Janeiro: DP\&A; Salvador, BA: UNEB, 2006.

TELES, Edilane Carvalho; SILVA, Elis Rejane S. . A Educação das maiorias: a educomunicação e a escola pública de qualidade. In: $41^{\circ}$ Congresso Brasileiro de Ciências da Comunicação, 2018, Joinville - SC. Intercom 2018 Univille. São Paulo: Intercom? Sociedade Brasileira de Estudos Interdisciplinares da Comunicação, 2018. p. $1-15$.

TURKLE, Sherry. La conversazione necessaria. La forza del dialogo nell'era digitale. Torino, Italia: Einaudi Editore, 2016. 